\title{
BiCyCLE NMES—neuromuscular electrical stimulation in the perioperative treatment of sarcopenia and myosteatosis in advanced rectal cancer patients: design and methodology of a phase II randomised controlled trial
}

Edward T. Pring 1,2,3,4* Daura E. Gould ${ }^{2,5}$, George Malietzis 2,3 , Philip Lung ${ }^{2}$, Mina Bharal ${ }^{2}$, Tutu Fadodun², Paul Bassett ${ }^{6}$, Mani Naghibi ${ }^{2}$, Claire Taylor ${ }^{2}$, Ioanna Drami ${ }^{2,3}$, Deeptika Chauhan ${ }^{2}$, Tamsyn Street ${ }^{7}$, Nader K. Francis ${ }^{8}$, Thanos Athanasiou, John M. Saxton ${ }^{9}$, John T. Jenkins ${ }^{2,3}$ and on behalf of the BiCyCLE Research Group

\begin{abstract}
Background: Colorectal cancer is associated with secondary sarcopenia (muscle loss) and myosteatosis (fatty infiltration of muscle) and patients who exhibit these host characteristics have poorer outcomes following surgery. Furthermore, patients, who undergo curative advanced rectal cancer surgery such as pelvic exenteration, are at risk of skeletal muscle loss due to immobility, malnutrition and a post-surgical catabolic state. Neuromuscular electrical stimulation (NMES) may be a feasible adjunctive treatment to help ameliorate these adverse side-effects. Hence, the purpose of this study is to investigate NMES as an adjunctive pre- and post-operative treatment for rectal cancer patients in the radical pelvic surgery setting and to provide early indicative evidence of efficacy in relation to key health outcomes.
\end{abstract}

Method: In a phase II, double-blind, randomised controlled study, 58 patients will be recruited and randomised (1: 1) to either a treatment (NMES plus standard care) or placebo (sham-NMES plus standard care) group. The intervention will begin 2 weeks pre-operatively and continue for 8 weeks after exenterative surgery. The primary outcome will be change in mean skeletal muscle attenuation, a surrogate marker of myosteatosis. Sarcopenia, quality of life, inflammatory status and cancer specific outcomes will also be assessed.

Discussion: This phase II randomised controlled trial will provide important preliminary evidence of the potential for this adjunctive treatment. It will provide guidance on subsequent development of phase 3 studies on the clinical benefit of NMES for rectal cancer patients in the radical pelvic surgery setting.

\footnotetext{
* Correspondence: e.pring17@imperial.ac.uk

'George Davies Research Fellowship, St Mark's Hospital, Harrow, UK

${ }^{2}$ Complex Cancer Clinic, St Mark's Hospital, Watford Road, Harrow HA1 3UJ,

UK

Full list of author information is available at the end of the article
}

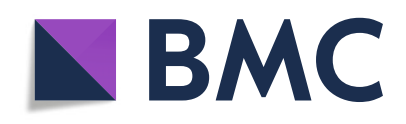

() The Author(s). 2021 Open Access This article is licensed under a Creative Commons Attribution 4.0 International License, which permits use, sharing, adaptation, distribution and reproduction in any medium or format, as long as you give appropriate credit to the original author(s) and the source, provide a link to the Creative Commons licence, and indicate if changes were made. The images or other third party material in this article are included in the article's Creative Commons licence, unless indicated otherwise in a credit line to the material. If material is not included in the article's Creative Commons licence and your intended use is not permitted by statutory regulation or exceeds the permitted use, you will need to obtain permission directly from the copyright holder. To view a copy of this licence, visit http://creativecommons.org/licenses/by/4.0/. The Creative Commons Public Domain Dedication waiver (http://creativecommons.org/publicdomain/zero/1.0/) applies to the data made available in this article, unless otherwise stated in a credit line to the data. 
Trial registration: Protocol version 6.0; 05/06/20. ClinicalTrials.gov NCT04065984. Registered on 22 August 2019; recruiting.

Keywords: Advanced rectal cancer, Sarcopenia, Myosteatosis, Rehabilitation, Exenteration surgery, NMES, Neuromuscular electrical stimulation

\section{Background}

Radical multi-visceral resection of pelvic tumours, known as pelvic exenteration, is being utilised to successfully treat a number of intra-abdominal malignancies [1]. Pelvic exenteration for locally recurrent (LRRC) or primary advanced rectal cancer has a high morbidity and mortality. The PelvEx Collaborative analysed data from 1184 patients, who underwent surgery for LRRC, and found that $2 \%$ of patients died within 30 days of surgery and $32 \%$ of patients experienced a major complication [2]. Despite this high morbidity and mortality, these complex procedures are increasingly practised in specialist centres. Following surgery, these patients enter a catabolic crisis where incapacitation and high protein and fat metabolism lead to a marked loss in skeletal muscle [3-5]. Low skeletal muscle mass (sarcopenia) and fatty infiltration (myosteatosis) are independently associated with poorer post-operative outcomes following surgery for colorectal cancer [6, 7]. The aetiology behind sarcopenia and myosteatosis is complex and multifactorial and includes inflammatory changes, hormonal changes, loss of function, fatigue and energy balance [8]. However, strategies to preserve skeletal muscle mass, quality and function may improve these outcomes.

A meta-analysis of resistance exercise training in patients with non-metastatic cancer showed significantly increased skeletal muscle mass [9]. Exercise can also impart an anti-inflammatory effect by attenuating the cellular response to inflammatory stimuli and proinflammatory cytokines such as IL-6, TNF $\alpha$ and TGF $\beta$ $[10,11]$. However, exercise programmes following a rectal cancer diagnosis and exenterative surgery are not always possible or practical due to patient anxieties and the need to expedite treatment, and the pain or disability associated with the extensiveness of the surgery itself. Furthermore, restriction upon rehabilitative resources, especially physiotherapy, often leaves patients immobile for long periods with resultant muscle atrophy. An alternative approach to traditional physiotherapy could be functional electrical stimulation (FES) via neuromuscular electrical stimulation (NMES). This is currently used in clinical practice for a number of diseases, indeed, at the National Clinical FES Centre at Salisbury, UK, over 2500 patients are currently undergoing FES [12]. NMES of the lower-limb muscles requires less motivation than traditional exercise and can be undertaken whilst the patient is seated or lying down [13]. NMES can be used to produce a muscle contraction equivalent to 20 to $40 \%$ of a maximum voluntary contraction [14] thus meeting the criteria of the American College of Sports medicine definition of planned exercise [15].

A study of anterior cruciate ligament [of the knee] (ACL) reconstruction patients by Hasegawa and colleague demonstrated NMES, implemented during the early rehabilitation stage, was effective in maintaining and increasing muscle thickness and strength in the operated limb [16]. There is also evidence from metaanalyses that NMES increases muscle strength and shows potential benefit for joint range of motion, muscle atrophy, outcomes of ventilation and activity limitations in critically ill patients [17]. A Cochrane review of NMES in a number of diseases that cause cachexia (muscle and fat loss secondary to disease) such as COPD (Chronic obstructive pulmonary disease), CCF (Congestive cardiac failure), HIV/AIDS and cancer, suggested that NMES may be an effective treatment for muscle weakness in adults with advanced progressive disease, and could be considered as a treatment within rehabilitation programmes [18]. Two studies, a phase 2 randomised trial and its pilot study, investigated NMES in cancer cachexia. Both studies were conducted in patients with non-small cell lung cancer receiving palliative chemotherapy [13, 19]. The pilot study [19] demonstrated positive results however, in the phase 2 study of 49 patients, in which 30 were randomised to NMES, there were no significant differences in quadriceps muscle strength, thigh lean mass or physical activity level between groups [13]. The study team did however recommend further NMES studies in patients with cancer in other settings. Notably these two studies by Maddocks' and colleagues focussed on palliative lung cancer patients; a surgical complex rectal cancer cohort is fundamentally different both by virtue of the impact of the insult of surgery on muscle but also the radical or curative nature of the treatment. The differences between these studies by Maddocks et al. and our study are summarised in Table 1.

Previous studies have examined NMES is the palliative setting, with inconclusive conclusions regarding efficacy $[13,19]$. No work has yet been done on clinical outcomes of NMES use in colorectal cancer nor any trial in the post-operative setting for cancer surgery. A phase II trial is required to determine whether there is evidence of a potential benefit prior to justifying a phase III study. 
Table 1 Differences between BiCyCLE NMES and earlier studies by Maddocks et al.

\begin{tabular}{ll}
\hline BiCyCLE NMES study population & Maddock's study population \\
\hline Post-operative "tumour free" & Active cancer \\
Confined to bed rest & Active and mobile population \\
Intensive inpatient support & Outpatient community care \\
Aiming for recovery up to or beyond baseline & Palliative and functionally declining population \\
\hline
\end{tabular}

The previous studies performed in cancer patients have not examined the relationship to the systemic inflammatory response, nor has there been an assessment of immediate post-operative outcomes. Our study aims to provide evidence of early indicative evidence of efficacy in relation to key health outcomes, including skeletal muscle mass and quality (myosteatosis), markers of systemic inflammation and post-operative recovery outcomes in rectal cancer patients undergoing radical pelvic surgery.

\section{Study design, methods and analysis}

The study is being undertaken at St Mark's Hospital, the sponsor in London North West University Healthcare (LNWH) NHS Trust. Details of the study sponsor and their roles and responsibility including auditing, indemnity and monitoring can be found in the full trial protocol provided as supplementary material, (page VIII and pages 24-26). Detailed information relating to the trial authors, management teams and committees including their roles and responsibilities can be found in the supplementary material full trial protocol under the relevant headings. Any amendments will be processed and communicated through the NHS Health Regulation Authority, Queens Square Research and Ethics committee and LNWH Research and Development Department, see Full Protocol pages 24-25 for further details.

Patients will be blinded as to which trial arm they enter and a sham protocol will be used by the control arm. Body composition analysis of the images will be done by automated software used by an assessor blinded to the intervention to remove operator or interpretation bias.

Our aim is to compare the effect on muscle of therapeutic NMES and current best practice against placebo NMES and current best practice alone in patients undergoing advanced radical surgery for complex rectal cancer.

\section{Outcomes}

\section{Primary outcome}

The difference in mean muscle attenuation (MA), of all skeletal muscle groups captured on the axial CT image at the level of the third lumbar vertebrate (L3), measured in Hounsfield units and hence the degree of myosteatosis between the pre-operative and 6-month post- operative CT scan in the NMES treatment group and the placebo NMES group.

\section{Secondary outcomes}

Our main secondary outcomes include change in total skeletal muscle cross-sectional area, at the L3 level between treatment and non-treatment groups as well as between time points for individual patients. Difference in quality of life between groups using the validated questionnaires ED-5Q-5L \& EORTC QLQ - CR29. Post-operative complications and length of hospital stay between both arms and comparison of the systemic inflammatory response between each group. A comprehensive list of secondary outcomes is shown in Table 2.

\section{Sample size estimation}

We powered this phase II trial based upon the primary outcome. Using data from the Alberta Cancer Registry, Martin and colleagues described a standard deviation of $\mathrm{MA}$ at 8.6 Hounsfield units (HU) for males and 10.2 HU for females [20]. We therefore assumed an overall mean SD of 9.4 HU for both male and female patients. A difference in MA between groups of $8 \mathrm{HU}$ was considered to be of clinical importance, and the calculation was based on showing a difference of this size between groups.

The proposed analysis will adjust the differences at 6 months for the MA values at baseline. To allow for this approach, this adjusted is included in the sample size calculation. The size of the association between baseline and outcome MA values is relatively unknown. A fairly weak correlation of about 0.3 between the time points was assumed.

The calculations were performed using a 5\% significance level and $90 \%$ power. Based on the information above, it was calculated that to show a difference in MA of 8 units between groups would require a sample size of 27 per group (54 patients in total).

To allow for an estimated dropout rate of 5\%, 58 patients will be recruited into the study. The dropout rate of $5 \%$ is an estimate based on the fact that the treatment period is short and supervised for the most part in hospital. For the primary outcome to be measured, we require the pre- and post-operative CT scans and therefore anticipate a very low dropout rate due to the fact these are routine scans and the time period is 
Table 2 Secondary outcomes

\begin{tabular}{|c|c|c|c|c|}
\hline Domain & Specific measurement & Metric & $\begin{array}{l}\text { Method of } \\
\text { aggregation }\end{array}$ & Time point \\
\hline $\begin{array}{l}\text { Lumbar } \\
\text { skeletal } \\
\text { muscle index } \\
\text { (LSMI) }\end{array}$ & $\begin{array}{l}\text { The difference in lumbar skeletal muscle } \\
\text { index (LSMI=height / area of skeletal } \\
\text { muscle in } \mathrm{cm}^{2} \text { at L3) derived from the } \\
\text { third lumbar vertebral axial level }\end{array}$ & $\begin{array}{l}\text { Change in LSMI at each } \\
\text { time point }\end{array}$ & $\begin{array}{l}\text { CT Scan; SliceOmatic } \\
\text { software version } 5.0 \\
\text { with ABACS L3 Plug- } \\
\text { in automation tool }\end{array}$ & $\begin{array}{l}\text { Pre-surgery } \\
3 \text { to } 6 \text { months post-surgery }\end{array}$ \\
\hline $\begin{array}{l}\text { Visceral } \\
\text { adipose tissue } \\
\text { (VAT) } \\
\text { Surface area }\end{array}$ & $\begin{array}{l}\text { Visceral adipose tissue area }\left(\mathrm{cm}^{2}\right) \\
\text { derived from the third lumbar vertebral } \\
\text { axial level }\end{array}$ & $\begin{array}{l}\text { Change in VAT at each time } \\
\text { point }\end{array}$ & $\begin{array}{l}\text { CT Scan; SliceOmatic } \\
\text { software version } 5.0 \\
\text { with ABACS L3 Plug- } \\
\text { in automation tool }\end{array}$ & $\begin{array}{l}\text { Pre-surgery } \\
3 \text { to } 6 \text { months post-surgery }\end{array}$ \\
\hline $\begin{array}{l}\text { Systemic } \\
\text { inflammation }\end{array}$ & C-Reactive Protein and serum albumin & $\begin{array}{l}\text { Modified Glasgow } \\
\text { Prognostic Score }\end{array}$ & $\begin{array}{l}\text { Ordinal values } \mathrm{mGPS}= \\
0 \mathrm{mGPS}=1 \mathrm{mGPS}=2\end{array}$ & $\begin{array}{l}\text { Preoperatively and } 6 \text { months post- } \\
\text { surgery }\end{array}$ \\
\hline $\begin{array}{l}\text { Cellular } \\
\text { immune } \\
\text { response }\end{array}$ & $\begin{array}{l}\text { Neutrophil count } \\
\text { Lymphocyte count }\end{array}$ & $\begin{array}{l}\text { Neutrophil to lymphocyte } \\
\text { ratio (neutrophil/ } \\
\text { lymphocyte count }\end{array}$ & $\begin{array}{l}\text { Clinically relevant } \\
\text { categorical cut off } \\
\text { values } \\
N L R<3 \\
N L R>3\end{array}$ & $\begin{array}{l}\text { Pre-operatively and } 6 \text { months post- } \\
\text { surgery }\end{array}$ \\
\hline $\begin{array}{l}\text { Post-operative } \\
\text { complications }\end{array}$ & Any post-operative complication & Clavien-Dindo Classification & $\begin{array}{l}\text { Clavien-Dindo Score } \\
1-5\end{array}$ & $\begin{array}{l}\text { Between } 0 \text { and } 90 \text { days post- } \\
\text { surgery }\end{array}$ \\
\hline $\begin{array}{l}\text { Length of } \\
\text { hospital stay }\end{array}$ & Inpatient stay post-surgery & Days & Median length of stay & From surgery to hospital discharge \\
\hline $\begin{array}{l}\text { Disease-free } \\
\text { survival }\end{array}$ & $\begin{array}{l}\text { Days to reported first recurrence / death } \\
/ 5 \text { years post-surgery }\end{array}$ & Days & $\begin{array}{l}\text { Kaplan-Meier survival } \\
\text { analysis }\end{array}$ & $\begin{array}{l}\text { From date of surgery to } 5 \text { years } \\
\text { post-surgery }\end{array}$ \\
\hline Overall survival & Days to death / 5 years post-surgery & Days & $\begin{array}{l}\text { Kaplan-Meier survival } \\
\text { analysis }\end{array}$ & $\begin{array}{l}\text { From date of surgery to } 5 \text { years } \\
\text { post-surgery }\end{array}$ \\
\hline \multirow[t]{2}{*}{$\begin{array}{l}\text { Quality of life } \\
\text { (General) }\end{array}$} & $\begin{array}{l}\text { EuroQol 5-level EQ-5D5L } \\
\text { Mobility, self-care, usual activities, }\end{array}$ & $\begin{array}{l}\text { Visual analogue scale score } \\
1-100 \text { and score in each of } \\
\text { the } 5 \text { domains }\end{array}$ & $\begin{array}{l}\text { Change in scores } \\
\text { between events }\end{array}$ & $\begin{array}{l}\text { Pre-surgery, } 6 \text { and } 12 \text { months post- } \\
\text { surgery }\end{array}$ \\
\hline & Pain/discomfort and anxiety/depression & & & \\
\hline $\begin{array}{l}\text { Quality of life } \\
\text { (colorectal } \\
\text { specific) }\end{array}$ & $\begin{array}{l}\text { EORTC QLQ - CR29 } \\
\text { Function and Symptoms }\end{array}$ & $\begin{array}{l}4 \text { multi-item scales and } 19 \\
\text { single items assessing com- } \\
\text { mon symptoms and prob- } \\
\text { lems in colorectal cancer }\end{array}$ & $\begin{array}{l}\text { Change in score } \\
\text { between events }\end{array}$ & $\begin{array}{l}\text { Pre-surgery, } 6 \text { and } 12 \text { months post- } \\
\text { surgery }\end{array}$ \\
\hline \multirow[t]{3}{*}{ Function } & Berg Balance Scale (BBS) & Berg balance score (0-56) & Change in BBS score & \multirow{4}{*}{$\begin{array}{l}\text { Pre-surgery and } 6 \text { months post- } \\
\text { surgery }\end{array}$} \\
\hline & 30 s sit to stand & $\begin{array}{l}\text { Number of full sit-to stand } \\
\text { actions completed in } 30 \mathrm{~s}\end{array}$ & $\begin{array}{l}\text { Change in number of } \\
\text { successful actions }\end{array}$ & \\
\hline & 6-min walk test & $\begin{array}{l}\text { Distance walked in } 6 \\
\text { minutes }\end{array}$ & Change in metres & \\
\hline $\begin{array}{l}\text { Thigh } \\
\text { circumference }\end{array}$ & $\begin{array}{l}\text { Thigh circumference, } 5 \mathrm{~cm} \text { above the } \\
\text { superior pole of the patella }\end{array}$ & Circumference in $\mathrm{cm}$ & $\begin{array}{l}\text { Change in thigh } \\
\text { circumference } \\
\text { between groups }\end{array}$ & \\
\hline $\begin{array}{l}\text { Dose response } \\
\text { to NMES }\end{array}$ & $\begin{array}{l}\text { Pre- and post-operative mean muscle at- } \\
\text { tenuation (L3) (MMA) and hours of de- } \\
\text { vice usage }\end{array}$ & Change in MMA/time & Linear regression & 3-6 months post-surgery \\
\hline $\begin{array}{l}\text { Patient } \\
\text { satisfaction }\end{array}$ & $\begin{array}{l}\text { Free text responses and satisfaction } \\
\text { scores derived from each domain (see } \\
\text { patient satisfaction survey } \\
\text { supplementary material). }\end{array}$ & $\begin{array}{l}\text { Qualitative and visual } \\
\text { analogue scale } 1-10\end{array}$ & $\begin{array}{l}\text { Qualitative responses } \\
\text { Median score } \\
\text { between groups on } \\
\text { each domain } \\
\text { assessed }\end{array}$ & 8 weeks post-surgery \\
\hline $\begin{array}{l}\text { Bioimpedance } \\
\text { analysis }\end{array}$ & Phase angle $=(\mathrm{Xc} / \mathrm{R})^{*} 180^{\circ} / \pi$ & $\begin{array}{l}\text { Cellular resistance }(R) \text { and } \\
\text { cellular reactance }(X c)\end{array}$ & $\begin{array}{l}\text { Change in phase } \\
\text { angle at each time } \\
\text { point }\end{array}$ & $\begin{array}{l}\text { Baseline, day } 2 \text { post operatively, } \\
\text { day } 28 \text { postoperatively (if in } \\
\text { hospital), day of discharge, first } \\
\text { post-operative follow-up } \\
\text { appointment }\end{array}$ \\
\hline
\end{tabular}

relatively short. The dropout rate for the secondary outcomes may be higher as the time from surgery progresses; however, the trial is powered to the primary outcome and as such, we are not taking into account the potential drop out from the trial outside this time period encompassing the primary outcome metrics. 


\section{Trial protocol}

\section{Recruitment and eligibility screening}

The inclusion and exclusion criteria are shown in Table 3. Following diagnosis of locally advanced rectal cancer patients is discussed in a multidisciplinary team (MDT) meeting. Some of these patients may be felt to be suitable for radical surgery-i.e., surgery performed with the intention of a cure. If patients are deemed fit for and consent to surgery then this is performed by one of three specialist surgeons in St Mark's Hospital, London, UK.

Patients who meet the inclusion criteria will be identified by the clinical team in the colorectal outpatient clinic or MDT and will then be approached by the study team with written information on the trial and given the option to enrol in the study. Consent to take part in the trial will be obtained at the next outpatient clinic appointment, which will occur in the weeks preceding surgery. Patients may be included in concomitant studies; provided agreement is obtained from each trial team. Further details regarding recruitment the strategy can be found on pages 21-22 of the Full Protocol (Supplementary Material).

Detailed information on participant withdrawal and discontinuation is provided on page 22 of the full protocol and within the consent and participant information sheet (supplementary material).

\section{Randomisation}

Randomisation, performed after the assessment of baseline outcomes, will take place by computer-generated randomisation software (https://www.sealedenvelope. com) on a one-to-one basis. Recruitment will be performed by the study team; randomisation will be performed by the study principal investigator. Patients who are randomised to the either arm will be blinded as to intervention and will be taught by the research team to use the stimulator; this will be at their clinic appointment following consent.

The NMES intervention lasts a total of 10 weeks with follow-up over 5 years. The trial algorithm is shown in Fig. 1 and schedule of enrolment, interventions and assessments in Fig. 2.

\section{Blinding}

Patients and the assessor of the primary outcome will be blinded. Patients will be blinded as to which arm they are in; the devices appear identical with the exception of a small, coloured plastic tab indicating whether they are treatment or placebo devices. The assessor of the primary outcome, a consultant radiologist, will be blinded as to which trial arm the participant is in; assessment of the primary outcome is also automated and therefore will not allow bias. The clinical team caring for the participant will not be aware of which trial arm the patient is in. It is not possible for the individuals providing the NMES therapy to be blinded as they will need to be aware of which arm the patient is in in order to provide effective advice.

\section{Data collection}

Surveillance CT scans performed as part of sequential screening (i.e. not emergency or non-routine imaging) are performed as standard in this patient group and will undergo analysis measuring mean muscle attenuation (myosteatosis) and muscle area (sarcopenia) at the level of the third lumbar vertebrate. Routine bloods including CEA (carcinoembryonic antigen) and inflammatory markers will be measured at each elective routine clinic visit and these data recorded, these samples will be collected, analysed and disposed of in accordance with the LNWH NHS Trust policy. Quality of life will be assessed at 6 and 12 months using validated quality of life questionnaires (ED-5Q-5L \& EORTC QLQ - CR29). The Berg Balance scale, 30-s sit-to-stand test and 6-min walk test [21-24] will be used to assess functional outcome these tests will be performed at the patients 3 months post operatively clinic appointment. Pre- and postoperatively, we will measure bilateral thigh circumference at $15 \mathrm{~cm}$ above the superior pole of the patella (which has been shown in earlier studies to correlate with muscle volume on MRI) [25]. Bio-impedance analysis (BIA) will be undertaken at baseline, day 2 postoperatively, day 28 post-operatively (if in hospital), day of discharge and first post-operative follow-up appointment. We will record data from the device satisfaction questionnaires from both groups. Standard outcome data and covariates to be collected are shown in Table 4 .

Table 3 Inclusion and exclusion criteria

\begin{tabular}{ll}
\hline Inclusion criteria & Exclusion criteria \\
\hline$\circ$ Adults age 18 and above & $\circ$ Lack of patient consent \\
$\circ$ Male or female & $\circ$ Widespread metastases not amenable to curative resection \\
$\circ$ Primary or recurrent locally advanced rectal cancer amenable & $\circ$ Contraindication to NMES \\
to elective radical exenterative surgery & $\circ$ Pre-existing neuromuscular degenerative disease \\
$\circ$ ASA grades I-III & $\circ$ Participation in other trials where agreement on participation not made in \\
$\circ$ Able and willing to consent & advance by trial teams \\
$\circ$ in other concurrent trials is acceptable_following discussion & $\circ$ Patients with solitary colon cancer above the level of the peritoneal reflexion \\
with trial team of both studies & which does not require complex pelvic surgery \\
\hline
\end{tabular}




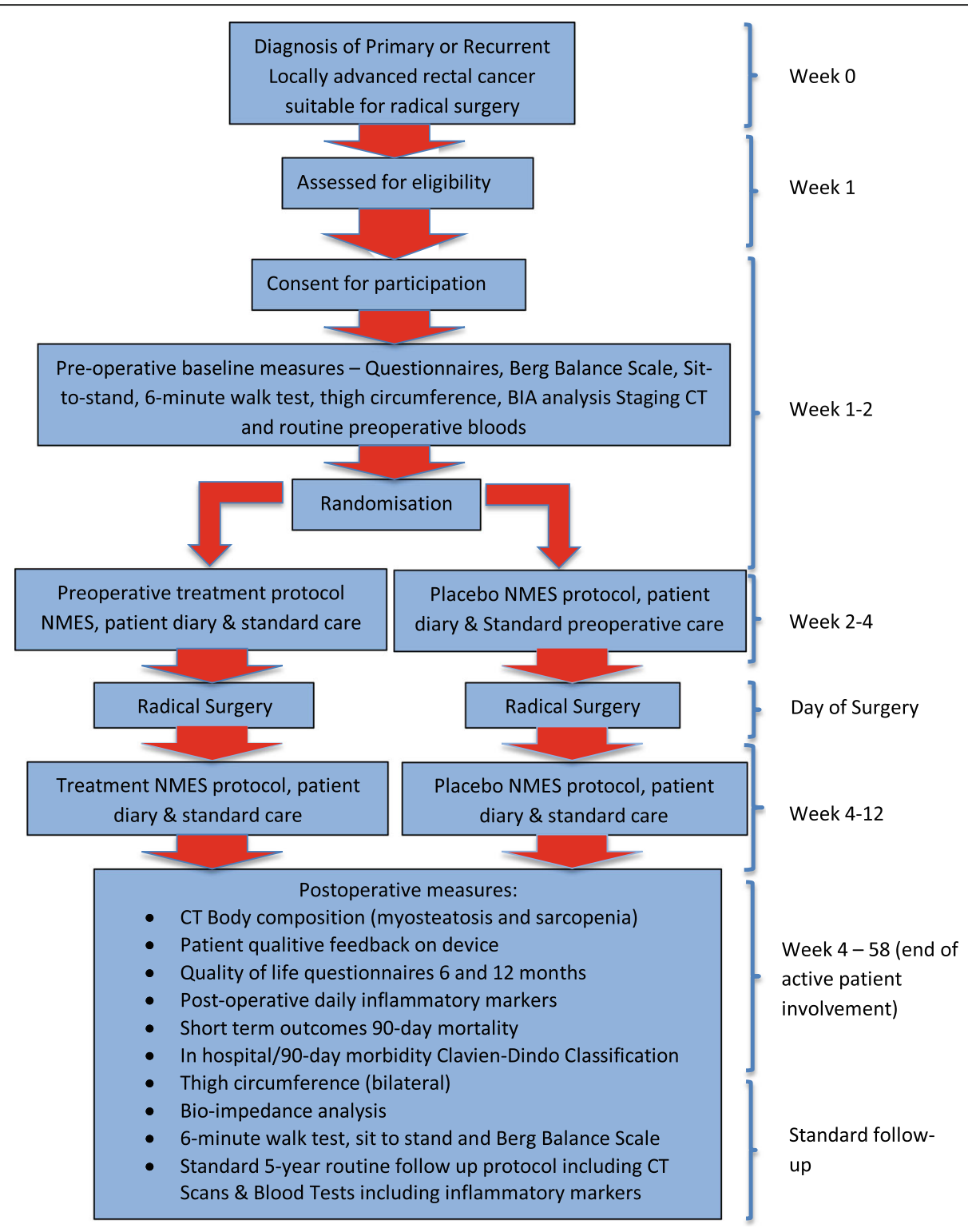

Fig. 1 Study algorithm

Data collection will be undertaken using a case report form (CRF) designed by the investigators; the data will be transferred from the CRF to a Microsoft Excel Database (Microsoft Corporation, Redmond, Washington, USA), stored in the LNWH NHS Trust secure network. All collected data will be reviewed by the principal investigator prior to analysis and specific searches on written notes or electronic record systems will be made to address any missing data points. The data collected as part of this trial will be subject to review by the independent Trial Data Monitoring committee on request as per the Data Monitoring Charter (supplementary material)."
Information on data management, storage and curation is available in the Full Trial Protocol (supplementary material, page 17).

\section{Data monitoring and compliance}

A sponsor-approved independent data monitoring committee (IDMC) has been appointed to the trial as part of good trial governance to ensure safety, scientific validity and integrity of the trial. The data monitoring committee will have access to raw data and will review any significant adverse events or safety concerns within the trial. The IMDC will make recommendations and report directly to the sponsor representative and chief 


\begin{tabular}{|c|c|c|c|c|c|c|c|c|c|}
\hline \multirow[t]{2}{*}{ Procedures } & \multicolumn{9}{|l|}{ Visits } \\
\hline & $\begin{array}{l}\text { Routine } \\
\text { Staging } \\
\text { CT either } \\
\text { at St } \\
\text { Mark's or } \\
\text { patients } \\
\text { home } \\
\text { hospital }\end{array}$ & $\begin{array}{l}\text { First } \\
\text { outpatient } \\
\text { clinic at } \\
\text { St Mark's }\end{array}$ & $\begin{array}{l}\text { Second } \\
\text { outpatient } \\
\text { appointment or } \\
\text { Pre-Assessment }\end{array}$ & $\begin{array}{l}\text { Surgical } \\
\text { Admission }\end{array}$ & $\begin{array}{l}\text { 4-8 weeks } \\
\text { post- } \\
\text { surgery }\end{array}$ & $\begin{array}{l}3-6 \\
\text { months }\end{array}$ & $\begin{array}{l}12 \\
\text { months }\end{array}$ & $\begin{array}{l}\text { Routine } 6 \\
\text { monthly follow } \\
\text { up } \\
\text { appointments } \\
\text { for } 5 \text { years } \\
\text { post-surgery }\end{array}$ & $\begin{array}{l}\text { Routine } 12 \\
\text { monthly follow up } \\
\text { appointments for } 5 \\
\text { years post-surgery }\end{array}$ \\
\hline Staging CT & $x$ & & & & & $x$ & $x$ & & $x$ \\
\hline Eligibility & & $x$ & & & & & & & \\
\hline $\begin{array}{l}\text { Medical history and } \\
\text { demographics }\end{array}$ & & $x$ & $\mathrm{x}$ & & & & & & \\
\hline Consent & & & $x$ & & & & & & \\
\hline Device Training & & & $x$ & $x$ & & & & & \\
\hline Device Use & & & $\mathrm{x}$ & $\mathrm{x}$ & $x$ & & & & \\
\hline Blood Tests & & & $x$ & $x$ & $x$ & $x$ & $x$ & $x$ & $x$ \\
\hline $\begin{array}{l}\text { Patient device } \\
\text { satisfaction } \\
\text { questionnaire }\end{array}$ & & & & & $\mathrm{x}$ & & & & \\
\hline $\begin{array}{l}\text { Patient QoL } \\
\text { Questionnaire }\end{array}$ & & & & & & $\mathrm{x}$ & $x$ & & \\
\hline $\begin{array}{l}\text { Bio-impedance } \\
\text { analysis (B|A) }\end{array}$ & & & $x$ & $x$ & $x$ & $x$ & & & \\
\hline
\end{tabular}

Fig. 2 Schedule of enrolment, interventions and assessments

investigator. The trial Data Monitoring Charter is included for review within the supplementary material. Further information on data management and security and storage are available in the Full Protocol, supplementary material pages 17, 26 and appendix 4 .

\section{Study intervention \\ Stimulation of muscle}

We will endeavour to stimulate two major muscle groups during the study, the quadricep muscles and paraspinal muscles. The muscles of the quadriceps, particularly vastus lateralis and vastus medialis, will be stimulated in both legs; this will be performed with a view to preserving muscle mass and encouraging earlier ambulation and better function.

We will also stimulate the erector spinae muscles and the muscles of the lower back. The reason for this is twofold: firstly, it is felt that some of the earliest muscles to atrophy following surgery or during bed rest are the core muscles of the back especially as these patients will not be sitting up or utilising these important supportive muscles in the first stages of their recovery. Patients are nursed on their side during the first 14 days following major pelvic surgery, which means they tend not to use

Table 4 Outcomes and covariates

\footnotetext{
Demographics

o Patient age

o Patent birth year

o Patient gender

o Patient ethnicity coding

o Weight

o Height

o Body mass index
}

\section{Disease}

o ASA grade (American College of Anaesthesiology) physical status

o Past medical history (other or previous illnesses and surgery)

\section{Cancer-specific characteristics}

o Type of cancer (primary/recurrent cancer, location and subtype on histology)

o Grade of cancer

o Stage of cancer

\section{Treatment factors}

o Details of surgery

o Chemotherapy

o Radiotherapy

\section{Outcome measures}

o 90-day post-operative complications (Clavien-Dindo classification

(18))

o Disease outcomes including 30-day survival

o Death / recurrence / disease-free survival

o Patient compliance diary data

o Device usage

\section{Body composition parameters}

o CT body composition at the level of the $L 3$ vertebra

o Bio-impedance analysis

o Anthropometric measurements

\section{Inflammatory markers}

o Serum C-reactive protein

o White cell count

o Serum albumin

o Platelet count

Patient-specific and functional outcomes

O Quality of life

- ED-5Q-5L

- EORTC QLQ - CR29

o Patient satisfaction 
their core muscles to flex or extend their back or support their weight leading to loss. This lateral position however would afford easy access to place the electrodes. Secondly, we are focussing on the muscle groups at the third lumbar vertebrate-the level this stimulation would take place, using the device in this location, would give us the best chance of demonstrating the benefits of the device with regard to muscle preservation. This site is well away from the operative site and tumour bed in these individuals and therefore there would be no risk of stimulating the tumour bed whilst using the device in this position.

Neuro-muscular stimulation will be delivered by a MicroStim Exercise Stimulator MS2v2 (Odstock Medical Limited (OML), Wiltshire, UK) using two self-adhesive electrodes placed on the anterior thigh over the body of the vastus medialis and lateralis and the muscles of the lower back. At their second clinic appointment at St Mark's, patients will be trained by the research fellow or other competent research team member (physiotherapist or specialist nurse) to use the NMES. A study-specific instruction leaflet will be given to this group along with the standard instruction manual by OML.

The programme will commence pre-operatively and consist of daily stimulation to one thigh at a time followed by the lower back each for $15 \mathrm{~min}$, increasing to 60 min within 1 week as tolerated. One treatment session for both thighs would last between 60 and $90 \mathrm{~min}$ in total per day-this can be taken in up to three discrete sessions. Treatment will last for 2 weeks preoperatively and 8 weeks postoperatively.

NMES would be used preoperatively to familiarise patients with and increase confidence in using the device prior to surgery and to aid prehabilitation.

\section{Intervention training}

Training in using the MicroStim 2v2 has been undertaken by the trial principal investigator at the device manufacturer, OML. Patient training will be conducted by the study PI or a trained member of their study team. Patients using the device will be observed and educated on correct usage by the study team. They will be asked to keep a usage diary and the device will record usage statistics via an inbuilt recorder. These data will feed into the analysis to provide a dose response model within the final analysis.

\section{The therapeutic NMES arm}

Patients will be blinded as to which arm of the trial they are in. Therapeutic NMES will be delivered by a MicroStim Exercise Stimulator MS2v2 using two self-adhesive electrodes placed on the anterior thigh over the body of the vastus medialis and vastus lateralis muscles and the lower back.
Pulse waveform (symmetrical biphasic squared), frequency $(40 \mathrm{~Hz})$, and width (350 microseconds) would be used for the duration of treatment with the NMES. The amplitude (device output 0-120 mA, tested across $1000 \Omega$ ) will be set to elicit a visible and comfortable muscle contraction; patients will be encouraged to subsequently increase the amplitude as tolerated. A "compliance diary" will be kept by the patients during their treatment period detailing their time spent using the device and the settings at which they are using it.

This programme is adapted from one found to be of benefit in a pilot study of patients with non-small cell lung cancer which itself was based on an NMES exercise programme developed for patients with COPD. The stimulation parameters were selected to favour gains in function and strength over endurance (frequency), minimise skin irritation (pulse width) and allow for sufficient recovery of the muscles between contractions (duty cycle) $[13,19]$.

\section{The placebo NMES arm}

A modified model of MicroStim Stimulator MS2v2 (Odstock Medical Limited, Wiltshire, UK) will be provided to the placebo group who will apply two selfadhesive electrodes placed on the anterior thigh over the body of the vastus medialis and vastus lateralis muscles and the lower back as in the treatment group. This placebo device will be programmed to provide subtherapeutic electrical stimulation. The device manufacturers have tailored a programme to come on and off at specified timings with ramps of specified duration. The placebo devices output is restricted to around $18 \mathrm{~V}$ and this gives little or no muscle recruitment. Patients will however perceive a sensation of electrical stimulation.

\section{Both groups}

Patients in both arms will receive standard care including enhanced nutritional support (parenteral nutrition for a minimum of 5 days or until taking sufficient calories enterally) and physiotherapy in line with current guidelines and local hospital practices. Routine daily blood tests for inflammatory markers will be taken until discharge.

\section{Assessment of outcomes}

Patients from both the treatment and control arms will receive standard 5-year follow-up. Histopathological data will be recorded following processing of the resected specimens by the pathologist. Quality of life data, patient satisfaction, bio-impedance analysis, CT Body composition and functional measurements will be taken as detailed below.

As a phase II trial, we aim to determine the short-term effects on our primary outcome; as such, our primary 
analysis to identify changes within the pre- and postoperative CT scans and analysis of NMES satisfaction and the initial inflammatory data, functional and quality of life data will take place at 6 months following the recruitment of the final patient with subsequent reporting and publication of these results. We will then continue long-term follow-up for the standard clinical 5-year follow-up period or until patient death. Final analysis exploring the effect of intervention on 5-year overall and disease-free survival will take place at 5 years following recruitment of the final patient.

\section{Body composition assessment CT body composition parameters}

CT image analysis using SliceOmatic version 5.0 software (TomoVision, Montreal, Quebec, Canada) will be performed. Total skeletal muscle and visceral adipose tissue surface area $\left(\mathrm{cm}^{2}\right)$ will be evaluated on a single image at the third lumbar vertebra (L3) using $\mathrm{HU}$ thresholds of -29 to 150 for skeletal muscle, -50 to 150 for visceral adipose tissue (VAT) and -190 to -30 for subcutaneous adipose tissues. CT body composition analysis of all the included images will undergo automated segmentation using the ABACS L3 automated plug-in software [26] (Voronoi Health Analytics, BC, Canada), which complements SliceOmatic. The automated process will be directed by a radiologist who will be blinded to the treatment group of individual patients. The automated segmentation process provided by the ABACS L3 plug-in also removes the possibility of operator bias in the analysis of the images. The sum of skeletal cross-sectional muscle areas will be normalised for stature $\left(\mathrm{m}^{2}\right)$ and reported as lumbar skeletal muscle index (LSMI) $\left(\mathrm{cm}^{2} / \mathrm{m}^{2}\right)$. Outcome variables will be continuous; categorical variables will be defined from these data using the cut-off values described earlier [20, 27, 28].

\section{Anthropometrics and bio-impedance analysis}

Bio-impedance analysis (BIA) will be undertaken using a SECA mBCA 525 analyser (SECA, Hamburg Germany). This will be performed at baseline, day 2 post-surgery, either hospital discharge or at 28 days post-surgery (whichever is first) and at 6 months. Patients will undergo analysis in a fasted state. Posterior upper arm skin fold thickness and waist circumference will be performed at baseline and 6 months. We will measure thigh circumference at $15 \mathrm{~cm}$ above the superior pole of the patella (which has been shown in earlier studies to correlate with muscle volume on MRI) [25]. Phase angle from BIA and patient BMI will be utilised as categorical variables with other outcome variables being continuous.

\section{Functional assessment}

It is important that we measure not only the anatomical effects of NMES, i.e. increased muscle mass on CT and anthropometric changes, but we identify whether these patients demonstrate both a functional and physiological improvement. To that end, we will assess functionality preoperatively at diagnosis and post-operatively at 3 months using the validated instruments of the 6-min walk test [24], $30 \mathrm{~s}$ sit-to-stand test [23] and Berg Balance scale (BBS) [21, 22]. These assessments will be undertaken in the complex cancer clinic by either a specialist physiotherapist or research fellow. These data will be treated as continuous outcome variables with the exception of BBS which will be categorical.

\section{Quality of life}

We will examine quality of life and patient experience of using the device. Quality of life will be measured using the validated questionnaires described above. On completing the intervention, participants will complete a questionnaire on compliance, comfort and usability of the device in the postoperative setting. Qualitative data and free text comments from this will also be collected.

\section{Systemic inflammatory response}

To monitor the inflammatory response, we will use commonly utilised postoperative inflammatory markers, namely c-reactive protein(CRP) and values derived from the full blood count and biochemistry including neutrophil-to-lymphocyte ratio (NLR) and modified Glasgow Prognostic Score (mGPS). These inflammatory markers are well-established metrics linked to both sarcopenia, myosteatosis and prognosis in colorectal cancer [29-31]. We have chosen these markers for a number of reasons; they are routinely taken and cost-effective and allow for comparison with substantial historical data. We may also require results from other trusts, due to the national spread of our patient population, and we cannot support them in obtaining non-routine tests as part of this study.

\section{Planned statistical analyses}

This study will be performed in line with the CONSORT criteria (http://www.consort-statement.org/consort-201 $0)$. Initially outliers, patterns of attrition and missing data will be identified using a combination of graphical displays and descriptive statistics allowing decisions on the assumption of normality. The primary analysis will be of observed data only, with patients with missing data omitted from the analysis. If the primary outcome has $>10 \%$ missing data points, a sensitivity analysis will be performed using multiple imputation to estimate the missing values. 
Data will be analysed by a statistician blinded to the intervention. Analyses of primary and secondary endpoints will be based on the full analysis set defined according to the intention to treat principle. Safety analysis will be performed for the on all enrolled individuals with disclosure of any significant adverse events. The full analysis set consists of all participants consented and randomised with valid baseline assessments. Participants will be analysed according to the study arm they were assigned at randomisation.

The primary outcome is myosteatosis at 3-6 months post-surgery, derived from the mean muscle attenuation on CT body composition analysis. This will be analysed using analysis of covariance (ANCOVA), with muscle attenuation values at baseline used as a covariate in the analysis.

The secondary outcome measures measured on a continuous scale, and with a baseline measurement will be analysed using equivalent methods as the primary outcome. For continuous outcomes with no baseline measurement, group comparisons will be made using either the unpaired $t$-test or Mann-Whitney test, depending on data distribution. The chi-square test, or Fisher's exact test, will be used to compare categorical outcomes between the study groups.

Significance will be assumed when $p<0.05$.

\section{Adverse event reporting}

Adverse event reporting in this trial is carried out in accordance with the NHS Health Regulation Authority (HRA). All serious adverse events (SAE), whether or not related to participation in the trial, will be reported immediately to the trial sponsor; these will be reviewed by the trial sponsor and should further investigation be required the trial sponsor may pause the trial to carry out investigation. Should a SAE occur as a direct result of the trial device or as a direct result of participation in the trial the trial will be paused and a non-CTIMP safety report form will be submitted to the relevant research and ethics committee with 15 days of the Chief Investigator becoming aware of the event. In this instance, the SAE report will be unblinded as required by the HRA. Patient-reported adverse events deemed expected or non-serious will be reported in the final publications arising from this trial, we expect many of these minor events to be reported in the patient satisfaction questionnaire.

\section{Discussion}

Patients who undergo major pelvic surgery have limited mobility due to postoperative pain and disability. These patients are therefore at much greater risk of suffering from muscle wasting than patients undergoing more routine colorectal surgery. This is a result of greater loss of function, greater immobility and potentially a more profound immunogenic inflammatory response.

Currently, these patients receive postoperative physiotherapy; due to limited time, postoperative pain, patient choice and resource availability, it is unlikely that the patients are exercised to their full potential. A prescribed programme with a NMES device would allow patients to choose when they undertake muscle stimulation exercise for example once they had received adequate analgesia or at a time convenient to them. This would hopefully improve compliance and bring about a hypertrophic response in the muscle.

We know that in muscle disuse in healthy individuals NMES may provide an effective treatment to preserve muscle volume [16]. Maddocks' work in cancer patients $[13,19]$ however did not demonstrate a significant increase in muscle volume and therefore one may question the rationale behind use in this patient group (these differences are summarised in Table 1). The cancer population in these studies is different from our own in a number of respects beyond the diagnosis alone and as such we may find NMES to be a more suitable intervention in our patient group. Maddocks' work was performed in a palliative population with active cancer whilst postoperatively our patients will be theoretically cancer free with perhaps a few exceptions in patients who have solitary metastases (which, by the criteria of inclusion, are amenable to curative treatment). In view of their palliative status, Maddocks' population would be expected to decline in health over time whilst our population would be expected to make a recovery up to or even beyond their preoperative state and therefore NMES may increase the rate of or facilitate this recovery. Our population is confined to bed rest for over a week's duration following surgery and therefore activity provided by NMES may help arrest the muscle loss associated with disuse as in Hasegawa's population whose anterior cruciate ligament repair cohort was subject to muscle loss through disuse rather than disease [16]. Finally, our patients will receive intensive inpatient support by the ward physiotherapists and the research team; they will receive positive reinforcement of their use of the device and will be asked to complete an exercise diary which the physiotherapy team, will review with them at each point they receive formal physiotherapy sessions. This level of direct input and positive reinforcement is notably more than in the previous NMES studies of Maddocks' and therefore we would hope compliance and correct usage would be increased.

The inflammatory effects of exercise are known to be paradoxical in that exercise drives both a pro and antiinflammatory response [32, 33]. We propose that the metabolic result of exercise in cancer patients will drive a beneficial anti-inflammatory response. This 
immunomodulation may in part help support the body's immune system in the early stages of post-surgical recovery and as such may potentially support the cellular immune system in being able to identify and destroy malignant cells shed at the time of surgery.

In our patient group, NMES will potentially allow a higher degree of exercise than the patients would otherwise be able to undertake due to their incapacity. Our hope is that this promotes muscle preservation, allowing earlier mobilisation and a more expedient return to "normal" exercise and function, further reinforcing the preservation of muscle mass. Increased muscle mass and quality are associated with improved long-term outcome such as disease-free survival [6] we intend to follow our cohort for 5 years to see if NMES provides evidence to support improvement in these oncological outcomes through muscle preservation.

\section{Summary}

Exercise in healthy individuals leads to increased muscle mass; exercise can bring about an anti-inflammatory effect due to muscle physiology thus obfuscating a key pathway driving secondary sarcopenia. Preservation of muscle mass through early post-operative intervention with NMES would allow a more rapid return to normal exercise and normal function leading to greater muscle preservation and subsequently improved outcomes.

\section{Trial status}

BiCyCLE NMES is currently recruiting patients; recruitment began on the 31 May 2019 and is expected to be completed by March 2021. Protocol version 6 dated 05/ $06 / 20$ is currently approved by the research ethics committee and the HRA.

\section{Supplementary Information}

The online version contains supplementary material available at https://doi. org/10.1186/s13063-021-05573-2.

\section{Additional file 1. \\ Additional file 2 \\ Additional file 3 .}

\section{Acknowledgements}

Dr Steven Crook Quality and Regulatory Manager, Odstock Medical Limited, Salisbury District Hospital, UK, for advising on device use, set up and development of placebo devices. The Independent Data Monitoring Committee: Mr Adam Stearns FRCS (Norfolk and Norwich NHS Foundation Trust, UK and University of East Anglia, UK) and Mr Christos Kontovounisios FACS, FRCS (Clinical Senior Lecturer Consultant Colorectal Surgeon, Imperial College London and The Royal Marsden NHS Foundation Trust). George and Arlene Davies for their support with the BiCyCLE research group.

\section{Authors' contributions}

ETP devised the trial and trial protocol, is trial principal investigator and tria coordinator. JTJ is the chief investigator. $L G, M B$ and $M N$ advised on nutritional aspects of the trial design and method. PL provided advice and support on the radiological input into the trial. TF, DC and JS provided advice and input into trial design on the exercise physiology and assessment. PB is the trial statistician. GM and TA advised on trial design and aspects of the trial relation to body composition and trial method. $\mathrm{CT}$ advised on nursing and patient centred factors and acted as a patient advocate. NKF and TS acted as independent peer reviewers of the trial and provided advice and feedback on the trial method and design. Further details of authorship eligibility and writing policy can be found in the Full Trial Protocol, supplementary material, pages 27-28. All authors read and approved the final manuscript.

\section{Funding}

Charitable funding received from the St Mark's Hospital Foundation (Reg. 1140930)

\section{Availability of data and materials}

Access to the final trial data set will be available to the trial team, the sponsor and for review by the independent data monitoring committee appointed by the sponsor.

\section{Declarations}

Ethics approval and consent to participate

The BiCyCLE NMES Trial (ClinicalTrials.gov Identifier: NCT04065984) is a single centre double blind, randomised controlled trial. Ethics approval for the study has been obtained from the NHS England HRA and Health and Care Research Wales (19/LO/0259). Local approval has been obtained by the Research and Development department of London North West University Healthcare NHS Trust (RD18/115). Informed consent is obtained from patients as part of the BiCyCLE NMES Trial; the approved participant information sheet and consent form (version 3 11/03/19) are included in the supplementary material.

\section{Consent for publication}

The sponsor has designated the right to publication to the authors. Trial participants have consented to publication of their analysed data and qualitative responses. The study findings will be of interest to surgical oncologist performing exenterative procedures for locally advanced cancers. This study will inform a future multi centre RCT to determine whether NMES is an effective post-surgical rehabilitation option in the surgical oncology patient.

\section{Competing interests}

The authors declare that they have no competing interests.

\section{Author details}

${ }^{1}$ George Davies Research Fellowship, St Mark's Hospital, Harrow, UK. ${ }^{2}$ Complex Cancer Clinic, St Mark's Hospital, Watford Road, Harrow HA1 3UJ, UK. ${ }^{3}$ Department of Surgery and Cancer, Imperial College, London W2 1NY, UK. ${ }^{4}$ Department of Surgery, St. Mark's Hospital, Watford Road, Harrow, Middlesex HA1 3UJ, UK. ${ }^{5}$ College of Medical Veterinary and Life Sciences, University of Glasgow, Glasgow G12 8QQ, UK. ${ }^{6}$ Statsconsultancy Ltd, Amersham, Bucks HP7 9EN, UK. ${ }^{7}$ Department of Clinical Science and Engineering, Salisbury District Hospital, Salisbury, UK. ${ }^{8}$ Department of Surgery, Yeovil District Hospital, Higher Kingston, Yeovil BA21 4AT, UK. 'Department of Sport, Exercise and Rehabilitation, Faculty of Health \& Life Sciences, Northumbria University, Newcastle Upon Tyne NE1 8ST, UK.

Received: 20 July 2020 Accepted: 27 August 2021

Published online: 15 September 2021

References

1. Brown KGM, Solomon MJ, Koh CE. Pelvic exenteration surgery: The evolution of radical surgical techniques for advanced and recurrent pelvic malignancy. Dis Colon Rectum. 2017;60(7):745-54. https://doi.org/10.1097/ DCR.0000000000000839.

2. Kelly ME, et al. Factors affecting outcomes following pelvic exenteration for locally recurrent rectal cancer. Br J Surg. 2018;105:650-7.

3. Maeda N, et al. Skeletal muscle loss in the postoperative acute phase after esophageal cancer surgery as a new prognostic factor. World J Surg Oncol. 2020;18:1-10. 
4. Hopkins JJ, Reif R, Bigam D, Baracos VE, Eurich DT, Sawyer MM. Change in skeletal muscle following resection of stage I-III colorectal cancer is predictive of poor survival: a cohort study. World I Surg. 2019;43(10):251826. https://doi.org/10.1007/s00268-019-05054-3.

5. Evans WJ. Skeletal muscle loss: Cachexia, sarcopenia, and inactivity. Am J Clin Nutr. 2010:91:1123-7.

6. Malietzis G, Currie AC, Athanasiou T, Johns N, Anyamene N, Glynne-Jones R, et al. Influence of body composition profile on outcomes following colorectal cancer surgery. Br J Surg. 2016;103(5):572-80. https://doi.org/10.1 002/bjs.10075

7. Cespedes Feliciano EM, et al. Association of systemic inflammation and sarcopenia with survival in nonmetastatic colorectal cancer. JAMA Oncol. 2017;94612:e172319.

8. Pring ET, Malietzis G, Kennedy RH, Athanasiou T, Jenkins JT. Cancer cachexia and myopenia-update on management strategies and the direction of future research for optimizing body composition in cancer-a narrative review. Cancer Treat Rev. 2018;70:245-54. https://doi.org/10.1016/j.ctrv.201 8.10.002.

9. Strasser B, Steindorf K, Wiskemann J, Ulrich CM. Impact of resistance training in cancer survivors: a meta-analysis. Med Sci Sports Exerc. 2013;45(11):208090. https://doi.org/10.1249/MSS.0b013e31829a3b63.

10. Keller C, Keller P, Giralt M, Hidalgo J, Pedersen BK. Exercise normalises overexpression of TNF-a in knockout mice. Biochem Biophys Res Commun. 2004;321(1):179-82. https://doi.org/10.1016/j.bbrc.2004.06.129.

11. Starkie R, Ostrowski SR, Jauffred S, Febbraio M, Pedersen BK. Exercise and IL6 infusion inhibit endotoxin-induced TNF-alpha productions in humans. FASEB J. 2003;17(8):884-6. https://doi.org/10.1096/fi.02-0670fje.

12. National Clinical FES Centre - Salisbury NHS Foundation Trust. Available at: http://www.salisbury.nhs.uk/INFORMATIONFORPATIENTS/DEPARTMENTS/ CLINICALSCIENCEANDENGINEERING/Pages/NationalClinicalFESCentre.aspx. (Accessed: 9th January 2018)

13. Maddocks $\mathrm{M}$, et al. Neuromuscular electrical stimulation of the quadriceps in patients with non-small cell lung cancer receiving palliative chemotherapy : a randomized phase II study. PLoS One. 2013;8:1-8.

14. Maffiuletti NA. Physiological and methodological considerations for the use of neuromuscular electrical stimulation. Eur J Appl Physiol. 2010;110(2):22334. https://doi.org/10.1007/s00421-010-1502-y.

15. Thompson W, Gordon N, Pescatello L. ACSM's guidelines for exercise testing and prescription. 8th Ed.: London Lippincott Williams Wilkins; 2010.

16. Hasegawa S, Kobayashi M, Arai R, Tamaki A, Nakamura T, Moritani T. Effect of early implementation of electrical muscle stimulation to prevent muscle atrophy and weakness in patients after anterior cruciate ligament reconstruction. J Electromyogr Kinesiol. 2011;21(4):622-30. https://doi.org/1 0.1016/j.jelekin.2011.01.005.

17. Burke D, Gorman E, Stokes D, Lennon O. An evaluation of neuromuscular electrical stimulation in. Clin Respir J. 2014:407-20. https://doi.org/10.1111/ framework.

18. Jones S, Man WDC, Gao W, Higginson IJ, Wilcock A, Maddocks M, et al. Neuromuscular electrical stimulation for muscle weakness in adults with advanced disease ( Review ). Cochrane Database Syst Rev. 2016;2016(10). https://doi.org/10.1002/14651858.CD009419.pub3.www.cochranelibrary.com.

19. Maddocks M, Lewis M, Chauhan A, Manderson C, Hocknell J. Randomized controlled pilot study of neuromuscular electrical stimulation of the quadriceps in patients with non-small cell lung cancer. J Pain Symptom Manag. 2009;38(6):950-6. https://doi.org/10.1016/.jpainsymman.2009.05.011.

20. Martin L, Birdsell L, MacDonald N, Reiman T, Clandinin MT, McCargar LJ, et al. Cancer cachexia in the age of obesity: Skeletal muscle depletion is a powerful prognostic factor, independent of body mass index. J Clin Oncol. 2013;31(12):1539-47. https://doi.org/10.1200/JCO.2012.45.2722.

21. Berg KO, Wood-Dauphinee SL, Williams JI, Maki B. Measuring balance in the elderly: validation of an instrument. Can J Public Health. 1992;83(Suppl 2): S7-11.

22. Berg K, Wood-Dauphinee S, Williams II. The Balance Scale: reliability assessment with elderly residents and patients with an acute stroke. Scand J Rehabil Med. 1995;27(1):27-36.

23. Jones CJ, Rikli RE, Beam WC. A 30-s chair-stand test as a measure of lower body strength in community-residing older adults. Res Q Exerc Sport. 1999; 70(2):113-9. https://doi.org/10.1080/02701367.1999.10608028.

24. ATS Committee on Proficiency Standards for Clinical Pulmonary Function Laboratories. ATS statement: guidelines for the six-minute walk test. Am J Respir Crit Care Med. 2002;166:111-7.
25. Chen $\mathrm{BB}$, et al. Thigh muscle volume predicted by anthropometric measurements and correlated with physical function in the older adults. $J$ Nutr Health Aging. 2011;15(6):433-8. https://doi.org/10.1007/s12603-010-02 81-9.

26. Dabiri S, Popuri K, Cespedes Feliciano EM, Caan BJ, Baracos VE, Beg MF. Muscle segmentation in axial computed tomography (CT)images at the lumbar (L3)and thoracic (T4)levels for body composition analysis. Comput Med Imaging Graph. 2019;75:47-55. https://doi.org/10.1016/j.compmedima g.2019.04.007.

27. Prado CM, Lieffers JR, McCargar $L$, Reiman T, Sawyer MB, Martin L, et al. Prevalence and clinical implications of sarcopenic obesity in patients with solid tumours of the respiratory and gastrointestinal tracts: a populationbased study. Lancet Oncol. 2008;9(7):629-35. https://doi.org/10.1016/S14 70-2045(08)70153-0.

28. Doyle SL, Bennett AM, Donohoe CL, Mongan AM, Howard JM, Lithander FE, et al. Establishing computed tomography-defined visceral fat area thresholds for use in obesity-related cancer research. Nutr Res. 2013;33(3): 171-9. https://doi.org/10.1016/j.nutres.2012.12.007.

29. Malietzis G, Johns N, al-Hassi HO, Knight SC, Kennedy RH, Fearon KCH, et al. Low muscularity and myosteatosis is related to the host systemic inflammatory response in patients undergoing surgery for colorectal cancer. Ann Surg. 2016;263(2):320-5. https://doi.org/10.1097/SLA.0000000000001113.

30. Abbass T, Dolan RD, Laird BJ, McMillan DC. The relationship between imaging-based body composition analysis and the systemic inflammatory response in patients with cancer: a systematic review. Cancers (Basel). 2019; 11(1-12). https://doi.org/10.3390/cancers11091304.

31. Malietzis G, Giacometti M, Askari A, Nachiappan S, Kennedy RH, Faiz OD, et al. A preoperative neutrophil to lymphocyte ratio of 3 predicts diseasefree survival after curative elective colorectal cancer surgery. Ann Surg. 2014; 260(2):287-92. https://doi.org/10.1097/SLA.0000000000000216.

32. Petersen AMW, Pedersen BK. The anti-inflammatory effect of exercise. J Appl Physiol. 2005;98(4):1154-62. https://doi.org/10.1152/japplphysiol.00164.2004.

33. Pedersen BK, Hoffman-Goetz L. Exercise and the immune system: regulation, integration, and adaptation. Physiol Rev. 2000;80(3):1055-81. https://doi. org/10.1152/physrev.2000.80.3.1055.

\section{Publisher's Note}

Springer Nature remains neutral with regard to jurisdictional claims in published maps and institutional affiliations.

Ready to submit your research? Choose BMC and benefit from:

- fast, convenient online submission

- thorough peer review by experienced researchers in your field

- rapid publication on acceptance

- support for research data, including large and complex data types

- gold Open Access which fosters wider collaboration and increased citations

- maximum visibility for your research: over $100 \mathrm{M}$ website views per year

At BMC, research is always in progress.

Learn more biomedcentral.com/submissions 